\title{
Research on Pilots Development Planning
}

\author{
Ruo Ding, Mingang Gao* \\ Institute of Policy and Management, Chinese Academy of Sciences, Beijing, China. \\ Email: ${ }^{*}$ mggao@casipm.ac.cn \\ Received October 25 $5^{\text {th }}, 2012$; revised November $24^{\text {th }}, 2012$; accepted December $3^{\text {rd }}, 2012$
}

\begin{abstract}
Pilot is one of the most important factors to ensure aviation safety. The article focuses on the Pilots Development Planning (PDP) problem. It is different from other countries that pilots are developed by airways themselves in China. Promotion of every pilot needs specified quantity of flight experience hours which are accumulated in daily flights. In the same time, the promotion routes of pilots are diversified. So keys of PDP problem are to estimate the number of pilots who have promotion qualification in different planning period and to optimize their promotion and transfer in all routes. After analyzing characteristics of pilot training, a PDP road map is drawn which shows the typical process for pilots' promotion and transfer. An optimization model which has promotion qualification constraints is built to solve PDP problem. According to different pilot development patterns, the method is proved to be effectively by a case study. The research has practical significance for Chinese airways.
\end{abstract}

Keywords: Aviation Safety; Pilots Development Planning; Promotion Qualification; Optimization Model

\section{Introduction}

It is urgent for Chinese civil aviation to train enough pilots in high-speed development period. It is either not easy to do so because airlines train pilots by themselves in China which is different from other countries. Based on the estimate of the future aviation market, airlines employ certain number of trainees from aviation academy to meet the demand of future pilots. At the same time, pilots employed by airlines are arranged to different types of planes to accomplish flight tasks according to demand. When the pilots have enough accumulated flight experience, they can promote or transfer to other aircraft types. It takes about four to seven years for a typical trainee to become a qualified captain. The number of qualified captains is one of the most important kinds of resource which determine the flight safety and development of airlines.

In recent years, Chinese civil aviation industry develops almost twice as fast as national economics. Forecasted by Boeing, Chinese annual average passenger growth rate is $7.6 \%$ and China will become the second largest market of the world in next 20 years [1]. Along with the fast increasing fleet size, the problem of pilots' resources shortage is always a burning question in civil aviation industry.

A scientifically reasonable plan of pilot development contributes to improve the operation economy and pro-

${ }^{*}$ Corresponding author. duction safety of airlines. The moment the trainees employed by the airlines, the airlines have to spend a lot on the trainees' training and operating. In case of pilot redundancy, the airlines will suffer from the increased financial burden and occupied fixed asserts. It influences airlines' development. Since the number of captains is required by the demand of market oriented flight, when the increase of co-pilots exceeds that of flight, the promotion of co-pilots has to be slowed. And the delayed promotion of co-pilots may influence the motion of copilots, which leads to the loss of co-pilots or influence the safety of flight due to the motion impact $[2,3]$. Therefore, effective medium- and long-term pilot development plans is necessary due to not only the safety but also the development of airlines.

Vassiliou $[4,5]$ has studied the foreign pilot training programming problem. By classified the pilots by their grade and discretizing the operating hour, and based on the hypothesis that the movement of different grades satisfy Markov quality [6] and statistics of history data, they established Markov analysis model. Georgiou et al. [7] further revised and improved Markov analysis model. Markov analysis model is suitable for the pilot human resources prediction to promote with no special control. Gao et al. [8] has also proofed that when the distribution of the increase for accumulation of flight experience hours is fixed the promotion of pilots is a Markov process. In fact, flight experience hours are accumulated during production process. Its increasing is affected by 
flight task, pilot-plane rate and the quality of task arrangement and is not always a fixed distribution.

In the field of pilot training planning, many scholars have done a lot based on optimization theory and system dynamics. Gao et al. [9] worked out the promotion estimate model in single type flight without considering the promotion indexes and the adjustment between fleets. Jia et al. [10] studied the pilots programming problem and describe it as a network flow model.

In this article, characteristics of pilot training in China are analyzed and we study a mathematical programming with which we try to solve PDP problem. In Section 2, a PDP road map is drawn. An optimization model which has promotion qualification constraints is built in Section 3. A case study is present to demonstrate the effectiveness of the optimization method in section of this article. In the last part conclusions are drawn.

\section{Pilots Development Planning Road Map}

The process of a typical trainee to captain has been showed in Figure 1. After graduating from aviation academy and employed by airline, trainees work on narrowbody fleet and transfer to wide-body fleet as co-pilot capacity. All types of co-pilots work on their flight and promote based on the accumulation of their operating hours. As for wide-body fleets, co-pilots could transfer to narrow-body fleet to promote to captains. The more hours accumulated in wide-body fleet, the fewer hours it takes for a co-pilot gets the qualification. When necessary, copilots in wide-body fleets could promote to captain without transferring, while a higher accumulation of operating hour is required.

In Figure 1, $C_{i}, i=1,2, \cdots, n$, means co-pilots with grade $i$ and $P$ means captains in each fleet. Fleet $\mathrm{A}$ is narrow-body fleet and Fleets $\mathrm{B}$ and $\mathrm{C}$ are wide-body fleets. The solid lines stand for the normal promotion routes and pilots will not take the dashed routes unless they are allowed to do so by the decision maker.

According to their demand every year in the future, captains are chosen from narrow-body aircrafts to be

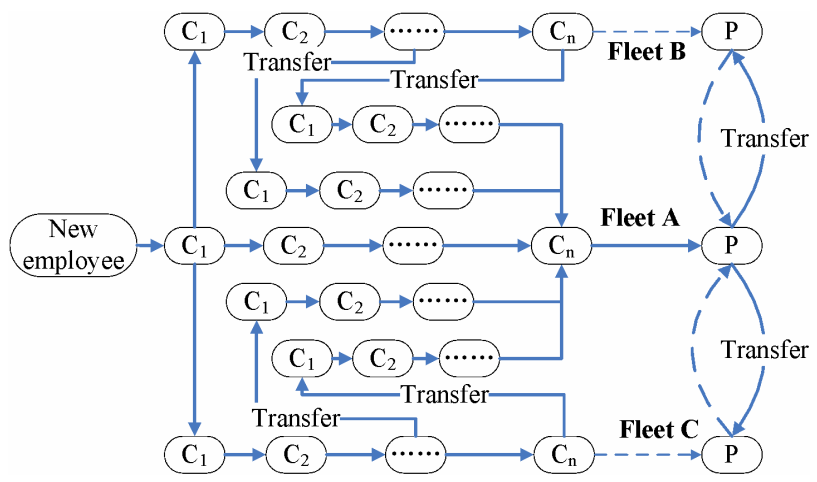

Figure 1. Example of PDP road map. trained and transferred to wide-body aircrafts. Then the demands of captains of all fleets are satisfied. The priority levels of different fleet determine the route and number of transferred pilots.

This research focuses on how to estimate the number of pilots who have promotion qualification and to optimize their promotion in all routes.

\section{Modeling}

In this part, a mathematical programming model is built to solve PDP problem.

\subsection{Variable List}

\section{Set list:}

$I$ : The set of Fleets.

$N$ : The set of co-pilots' grades.

$\Pi$ : The set of co-pilots who transferred from other fleets.

$J$ : Years during planning period.

\section{Variable list:}

$C_{n-1, n, \eta, i, j}$ : The number of co-pilots who transferred from Grade $n$ of other fleets and will promote from grade $n-1$ to grade $n$ in Fleet $i$ during Year $j$.

$C z_{n, i, h, j}$ : The total number of co-pilots who will transfer from Grade $n$ of Fleet $i$ to Fleet $h$ in Year $j$.

$P z_{i, h, j}$ : The number of captains who will transfer from Fleet $i$ to Fleet $h$ in Year $j$.

$P p_{i, j}$ : The gap of captains in Fleet $i$ in Year $j$.

$\omega_{n, \eta, i, j, k}$ : The number of co-pilots who will transfer from $k$ th interval of accumulated flight experience hours of Grade $n$ to Fleet $i$ in Year $j$.

$g z_{i, h, j}$ : The number of co-pilots who have qualification to transfer from Fleet $i$ to Fleet $h$ in Year $j$.

\section{Parameter list:}

$a_{i, n, \eta}$ : The required accumulated flight experience hours for co-pilot with Grade $n$ to promote in Fleet $i$.

$\delta u_{n, i}, \delta d_{n, i}$ : The maximum and minimum estimated values of increase flight experience hours in one year for co-pilot with Grade $n$ in Fleet $i$.

$A d_{i, n}$ : The probability for co-pilot with Grade $n$ to build $\delta d_{n, i}$ flight experience hours in one year in Fleet i.

$R a_{n, n+1, i}:$ The proportion of co-pilots who will promote from Grade $n$ to Grade $n+1$ in all qualified co-pilots in Fleet $i$.

$V S_{n, i, j}$ : The cost for one co-pilot with Grade $n$ to promote in Fleet $i$ in Year $j$.

$V c z_{n, i, h, j}$ : The cost for one co-pilot with Grade $\eta$ to transfer from Fleet $i$ to Fleet $h$ in Year $j$.

$V p z_{i, h, j}$ : The cost for one captain to transfer from Fleet $i$ to Fleet $h$ in Year $j$.

$V p p_{i}, V c p_{i}$ : The penalty fee for one gap of captain and co-pilot. 
$R t p_{i, j}, R t c_{i, j}$ : The numbers of retired captains and co-pilots.

$Z g_{n, n+1, i, j}$ : The number of new co-pilots with grade $n+$ 1 in Fleet $i$ in Year $j$.

$\theta_{i, h}$ : The minimum limit for co-pilots who will transfer from Fleet $i$ to Fleet $h$ every year.

$D p_{i, j}, D c_{i, j}$ : The demands for captains and co-pilots in Fleet $i$ in Year $j$.

$g_{\eta, i, j}$ : The number of co-pilots who have qualification to promote to captains now.

$R c_{n, \eta, i, j}$ : The number of co-pilots with Grade $n$ now who transferred from Grade $\eta$ in Fleet $i$ in Year $j$.

$R p_{i, j}$ : The number of captains in Fleet $i$ in Year $j$.

$f_{n, \eta, i, j, k}$ : The number of co-pilots in $k$ th interval of accumulated flight experience hours with Grade $n$ in Fleet $n$ now who transferred from Grade $\eta$ in Year $j$.

$\sigma_{i, j}$ : The total number of pilots who will transfer to Fleet $i$ in Year $j$.

\subsection{Optimization Model}

$$
\begin{aligned}
& \min \sum_{j \in J}\left\{\sum_{i \in I} \sum_{n \in N} \sum_{\eta \in \Pi}\left(V s_{n, i, j} \times C_{n-1, n, \eta, i, j}\right)+\sum_{i, h \in I \& \& i \neq h} \sum_{\eta \in \Pi}\left(V c z_{n . i . h . j} \times C z_{n, i, h, j}\right)+\sum_{i, h \in I \& i \neq h}\left(V p z_{i, h, j} \times P z_{i, h, j}\right)\right. \\
& \left.+\sum_{i \in I}\left(V p p_{i, j} \times P p_{i, j}+V c p_{i, j} \times C p_{i, j}\right)\right\} \\
& l_{n, \eta, i, j, k}=\left\{\left(1-A d_{i, n}\right) \times\right. \\
& 0 \\
& A d_{i, n} \times f_{n, \eta, i, j-1, k-\delta d_{n, i}}-\sum_{h \in I /\{i\}} \omega_{n, \eta, i, h, j, k} \\
& 0<k \leq \delta d_{n, i}+a_{i, n, \eta} \\
& \delta d_{n, i}+a_{i, n, \eta}<k \leq \delta u_{n, i}+a_{i, n, \eta} \\
& \delta u_{n, i}+a_{i, n, \eta}<k \leq \delta d_{n, i}+a_{i, n+1, \eta} \\
& \left(1-A d_{i, n}\right) \times f_{n, \eta, i, j-1, k-\delta u_{n, i}}-\sum_{h \in I /\{i\}} \omega_{n, \eta, i, h, j, k} \\
& \delta d_{n, i}+a_{i, n+1, \eta}<k \leq \delta u_{n, i}+a_{i, n+1, \eta} \\
& k>\delta u_{n, i}+a_{i, n+1, \eta} \\
& f_{n, \eta, i, j, k}= \begin{cases}l_{n, \eta, i, j, k}+l_{n-1, \eta, i, j, k}+F_{n-1, n, \eta, i, j}+\sigma_{n, i, j} \quad a_{i, n, \eta}<k \leq a_{i, n, \eta}+\delta u_{n-1, i} \\
l_{n, \eta, i, j, k} \\
0 & a_{i, n, \eta}+\delta u_{n-1, i}<k \leq a_{i, n+1, \eta} \\
k \leq a_{i, n, \eta} \quad \text { or } \quad k>a_{i, n+1, \eta}\end{cases} \\
& \sum_{r=1}^{j-1} C_{n, n+1, \eta, i, r}+C_{n, n+1, \eta, i, r} / R a_{n, n+1, \eta, i} \leq \sum_{r=1}^{j}\left[Z g_{n, n+1, \eta, i, r}-(\lfloor n / \hat{n}\rfloor) \times\left(g_{\eta, i}-\sum_{h \in I /\{i\}} g z_{i, h, j}\right)\right] \\
& R c_{n, i, j}=\sum_{\eta \in \Pi}\left(R c_{n, \eta, i, j-1}-C z_{n, i, h, j}+\sigma_{n, i, j}-C_{n, n+1, \eta, i, j}+C_{n-1, n, \eta, i, j}\right)-(\lfloor n / \hat{n}\rfloor) \times\left(R t c_{i, j}+\sum_{h \in I /\{i\}} g z_{i, h, j}\right)
\end{aligned}
$$

$\sum_{n \in N} \sum_{\eta \in \Pi} R c_{n, \eta, i, j}+R p_{i, j}+P p_{i, j} \geq D p_{i, j}+D c_{i, j}$

The objective function (1) is to minimize the total cost which includes promotion costs, transfer costs and penalty fee for lack of captains. We adjust the priorities of co-pilots' promotion by $V s_{n, i, j, p}$. For example, when $V s_{n, i, j+1, p} \leq V s_{n, i, j, p}$, the promotion will be planned as later as possible.

The step function (2) and (3) is used to estimate the accumulated flight experience hours for each co-pilot.

With the promotion requirements, we can estimate the number of pilots who newly get the promotion qualification in different planning period by Formula (6).

Formula (4) constrains the number of co-pilots who will promote to captains and ensures the flight operation level for good-skill co-pilots.

Formulas (7) and (8) calculate the number of transferred co-pilots and their grades. Formula (9) constrains the minimum number of co-pilots to transfer. It ensures 
co-pilots to promote to captains in the future.

Formulas (10) and (11) mean that pilots must meet their demands every year.

Formulas (5) and (12) are flow balance constraints for pilots.

\section{Case Study}

In order to demonstrate the effectiveness of the optimization model, a case with two scenarios according to simulated data of some airline company is studied in this section. Three fleets are present as Fleet A, B and C. Fleet A is a narrow-body fleet while the other two are wide-body fleets.

\subsection{Scenario One}

At the beginning of planning period, the staff in all fleets is shown in Table 1.

First of all, we consider a situation where all the fleets are increasing at 12 percent annually in the next five years in Chinese civil aviation industry. In this case, the future demands of captains and co-pilots are calculated and showed in Table 2.

Table 1. The staff in all fleets at the beginning of planning period.

\begin{tabular}{ccccc}
\hline \multirow{2}{*}{$\begin{array}{c}\text { The number of } \\
\text { pilots }\end{array}$} & Co-pilot & $\begin{array}{c}\text { Demand of } \\
\text { co-pilot }\end{array}$ & Captain & $\begin{array}{c}\text { Demand of } \\
\text { captain }\end{array}$ \\
\cline { 2 - 5 } Fleet A & 248 & 253 & 240 & 230 \\
Fleet B & 126 & 99 & 93 & 90 \\
Fleet C & 141 & 212 & 160 & 192 \\
\hline
\end{tabular}

Table 2. The future demand of captains and co-pilots in all fleets.

\begin{tabular}{ccccccc}
\hline \multirow{2}{*}{$\begin{array}{c}\text { The demand of } \\
\text { pilots }\end{array}$} & \multicolumn{3}{c}{ The demand of co-pilots } & \multicolumn{3}{c}{ The demand of captains } \\
\cline { 2 - 7 } & Fleet A & Fleet B & Fleet C & Fleet A & Fleet B & Fleet C \\
\hline Year 1 & 286 & 99 & 229 & 260 & 90 & 208 \\
Year 2 & 319 & 110 & 256 & 290 & 100 & 232 \\
Year 3 & 352 & 121 & 282 & 320 & 110 & 256 \\
Year 4 & 391 & 132 & 308 & 355 & 120 & 280 \\
Year 5 & 435 & 143 & 344 & 395 & 130 & 312 \\
\hline
\end{tabular}

Based on the above input data, the programming model is run by LINGO 9.0 which is a simple tool for utilizing the power of linear and nonlinear optimization to formulate large problems. The main purpose of LINGO is to allow a user to quickly input a model formulation, solve it, assess the correctness or appropriateness of the formulation based on the solution, quickly make minor modifications to the formulation, and repeat the process. We get the results as follows.

Table 3 is the planned number of captains and its gap in all years of planning period. Based on the estimated developing rate, the reserve of staff is insufficient at the beginning of planning period. Therefore, there is captain gap in the first three years, which is coincided with the fact. After the reasonable adjustment in the last two years, the supply and the demand of captain are balanced.

Table 4 is the adjustment of captains during planning period.

Table 5 is the promotion of co-pilots in all years during planning period. In the first three years, all qualified co-pilots promote to captains because the existence of captain insufficiency. In the last two years, only parts of co-pilots promote.

Table 6 shows the number of transferred copilots every year. In the first three years, demand for captains is very large, so co-pilots more than the minimum number are recommended to participate transfer training so as to promote to captains in the future. In the last two years, the number of transferred co-pilots equals to the minimum number.

Table 7 shows the recommendations of enrolling new employees during the planning period.

\subsection{Scenario Two}

Due to the development demand of Chinese civil aviation industry, some types of aircraft will retire in next few years. The pilots of retired aircraft will be arranged to other fleets according to the requirement. In response to this reality, we have designed a scenario: the scales of Fleets $\mathrm{A}$ and $\mathrm{C}$ are still developing by average annual rate of $12 \%$, while Fleet B will complete retirement in the next five years.

Table 8 shows the demand of captains and co-pilots in all types of aircraft in the next five years.

Table 3. The planned number of captains and its gap in all fleets.

\begin{tabular}{cccccc}
\hline \multirow{2}{*}{\begin{tabular}{c} 
The number of $\begin{array}{c}\text { Fleet A } \\
\text { captains }\end{array}$ \\
\cline { 2 - 6 }
\end{tabular}} & $\begin{array}{c}\text { The number of } \\
\text { captains }\end{array}$ & The gap of captains & $\begin{array}{c}\text { The number of } \\
\text { captains }\end{array}$ & $\begin{array}{c}\text { The gap of captains } \\
\text { The number of } \\
\text { captains }\end{array}$ & $\begin{array}{c}\text { The gap of captains } \\
\text { Year 1 }\end{array}$ \\
Year 2 & 255 & 5 & 93 & -3 & 0 \\
Year 3 & 302 & 32 & 100 & 0 & 232 \\
Year 4 & 355 & 18 & 110 & 0 & 256 \\
Year 5 & 395 & 0 & 130 & 0 & 0 \\
\hline
\end{tabular}


Table 4. The planned number of captains transferred to every fleet.

\begin{tabular}{cccccc}
\hline & \multicolumn{3}{c}{ Year } & \\
The number of captains & 1 & 2 & 3 & 4 & 0 \\
\hline Fleet A & 0 & 0 & 0 & 10 & 10 \\
Fleet B & 0 & 7 & 10 & 24 & 36 \\
Fleet C & 48 & 24 & 24 & 0 \\
\hline
\end{tabular}

Table 5. The number of co-pilots promote to captains in Fleet A.

\begin{tabular}{cccccc}
\hline & \multicolumn{5}{c}{ Year } \\
\cline { 2 - 6 } The number of captains & 1 & 2 & 3 & 4 & 5 \\
\hline Qualified & 53 & 61 & 87 & 130 & 37 \\
Promoted & 53 & 61 & 87 & 99 & 23 \\
\hline
\end{tabular}

Table 6. The number of co-pilots which convert aircraft type in each year during planning period.

\begin{tabular}{ccccc}
\hline & \multicolumn{2}{c}{ Fleet B } & \multicolumn{2}{c}{ Fleet C } \\
\cline { 2 - 5 } The number of co-pilots & $\begin{array}{c}\text { The minimum number of } \\
\text { transferred co-pilots }\end{array}$ & $\begin{array}{c}\text { The planned number of } \\
\text { transferred co-pilots }\end{array}$ & $\begin{array}{c}\text { The minimum number of } \\
\text { transferred co-pilots }\end{array}$ & $\begin{array}{c}\text { The planned number of } \\
\text { transferred co-pilots }\end{array}$ \\
\hline Year 1 & 14 & 84 & 12 & 75 \\
Year 2 & 10 & 10 & 10 & 23 \\
Year 3 & 11 & 11 & 28 & 26 \\
Year 4 & 12 & 12 & 31 & 31 \\
Year 5 & 13 & 13 & 28 \\
\hline
\end{tabular}

Table 7. Recruiting plan of new employees in each year of planning period.

\begin{tabular}{cccccc}
\hline \multirow{2}{*}{ The number of new employees } & \multicolumn{5}{c}{ Year } \\
\cline { 2 - 6 } & 1 & 2 & 3 & 4 & 5 \\
\hline Fleet A & 171 & 95 & 147 & 163 & 173 \\
\hline
\end{tabular}

Table 8. The future demand of captains and co-pilots in all fleets.

\begin{tabular}{|c|c|c|c|c|c|c|}
\hline \multirow{2}{*}{ The demand of pilots } & \multicolumn{3}{|c|}{ The demand of co-pilots } & \multicolumn{3}{|c|}{ The demand of captains } \\
\hline & Fleet A & Fleet B & Fleet $\mathrm{C}$ & Fleet A & Fleet B & Fleet $\mathrm{C}$ \\
\hline Year 1 & 286 & 99 & 229 & 260 & 90 & 208 \\
\hline Year 2 & 314 & 88 & 256 & 285 & 80 & 232 \\
\hline Year 3 & 341 & 66 & 282 & 310 & 60 & 256 \\
\hline Year 4 & 344 & 33 & 308 & 340 & 30 & 280 \\
\hline Year 5 & 407 & 0 & 344 & 370 & 0 & 312 \\
\hline
\end{tabular}

We can get the following planning proposals by LINGO 9.0.

Tables 9 and 10 shows that along with the shrink of Fleet B, its captains decrease year by year and can meet the demand. And the gaps of captains in the other fleets have also greatly reduced compared with Scenario one.
For Fleet $C$, the gap of captains is -4 . It means that the number of captains is more than its demand in the last year of planning period because of receiving captains from Fleet B.

Table 11 shows that the demand for new employees is greatly reduced compared with Scenario one because of 
Table 9. The planned number of captains and its gap in all fleets.

\begin{tabular}{ccccccc}
\hline & \multicolumn{2}{c}{ Fleet A } & \multicolumn{2}{c}{ Fleet B } & \multicolumn{2}{c}{ Fleet C } \\
\cline { 2 - 7 } The number of captains & $\begin{array}{c}\text { The number of } \\
\text { captains }\end{array}$ & The gap of captains & $\begin{array}{c}\text { The number of } \\
\text { captains }\end{array}$ & The gap of captains & $\begin{array}{c}\text { The number of } \\
\text { captains }\end{array}$ & The gap of captains \\
\hline Year 1 & 258 & -2 & 90 & 0 & 208 & 0 \\
Year 2 & 278 & -7 & 80 & 0 & 232 & 0 \\
Year 3 & 310 & 0 & 60 & 0 & 256 & 0 \\
Year 4 & 370 & 0 & 30 & 0 & 316 & -4 \\
Year 5 & 370 & 0 & 0 & 0 & 0 \\
\hline
\end{tabular}

Table 10. The planned number of captains transferred to every fleet.

\begin{tabular}{cccccc}
\hline \multirow{2}{*}{ The number of captains } & \multicolumn{5}{c}{ Year } \\
\cline { 2 - 6 } & 1 & 2 & 3 & 4 & 5 \\
\hline Fleet A & 0 & 0 & 0 & 0 & 0 \\
Fleet B & 0 & 0 & 0 & 0 & 0 \\
Fleet C & 48 & 24 & 24 & 24 & 36 \\
\hline
\end{tabular}

Table 11. Recruiting plan of new employees in each year of planning period.

\begin{tabular}{cccccc}
\hline \multirow{2}{*}{ The number of new employees } & \multicolumn{5}{c}{ Year } \\
\cline { 2 - 6 } & 1 & 2 & 3 & 4 & 5 \\
\hline Fleet A & 162 & 78 & 67 & 50 & 68 \\
\hline
\end{tabular}

the retirement of Fleet $\mathrm{B}$.

In the above scenarios, the optimization method presents reasonable and effective planning proposals. It has certain practical significance for Chinese civil aviation.

\section{Conclusions}

Chinese aviation industry is in its high-speed development period. Good pilots-develop plans are urgently needed for both flight safety and economic benefit. The article studies PDP problem by building an optimization model with which we estimate the number of pilots who have promotion qualification in different planning period and optimize their promotion and transfer in all routes. The model is an integer programming with promotion qualification constraints and its objective is to minimize the total cost which includes promotion costs, transfer costs and penalty fee for lack of captain.

The optimization method is demonstrated to be effective by a case study with two different scenarios. It provides a good theoretical support for human resource planning of Chinese airways.

The integer programming is solved by LINGO 9.0. In the future research, it may be replaced by a heuristic algorithm which may be more effective.

\section{REFERENCES}

[1] "Long-Term Market," 2011. http://www.boeingchina.com/

[2] H. J. Wang, "Airline Pilot Selection and Management," China Civil Aviation, Vol. 124, 2011, pp. 15-18.

[3] H. Liang, "Crack's Flow of Civil Aviation Pilots," $\mathrm{Hu}$ man Resource, Vol. 7, 2008, pp. 68-69.

[4] P. C. G. Vassiliou, "Asymptotic Behavior of Markov Systems," Journal of Applied Probability, Vol. 19, No. 4, 1982, pp. 851-857. doi:10.2307/3213839

[5] P.-C. G. Vassiliou, "The Evolution of the Theory of NonHomogeneous Markov Systems," Applied Stochastic Models and Data Analysis, Vol. 13, No. 3-4, 1997, pp. 159-176. doi:10.1002/(SICI)1099-0747(199709/12)13:3/4<159::AI D-ASM309>3.0.CO;2-Q

[6] D. J. Bartholomew, A. F. Forbes and S. I. McClean, "Statistical Techniques for Manpower Planning," John Wiley \& Sons, Hoboken, 1991.

[7] A. C. Georgiou and N. Tsantas, "Modelling Recruitment Training in Mathematical Human Resource Planning," Applied Stochastic Models in Business and Industry, Vol. 18, No. 1, 2002, pp. 53-74. doi:10.1002/asmb.454

[8] M. G. Gao and H. Chi, "Promotion Cycle Analysis of Pilots," Operations Research and Management Science, 
Vol. 3, 2012, pp. 99-104.

[9] M. G. Gao, B. G. Xu, et al., "A Position Elevating Model for Pilot Training for Airways," Proceedings of 2008 International Conference on Management Science and Engineering Management, Chongqing, 3-8 November 2008,

\section{pp. 705-710.}

[10] C.-L. Jia and B.-G. Xu, "Human Resource Programming Model for Pilots in Airline Company Based on Network Flow Theory," Chinese Journal of Management Science. Vol. 13, 2005, pp. 419-422. 